\title{
Effect of Glucose Oxidase on the Cytokine Profile and Cholesterol of Monocytes in Liver Cancer
}

\author{
Souad Zoudji, Mourad Aribi and Mustapha Haddouche* \\ Laboratory of Applied Molecular Biology and Immunology, Abou-Bekr University, ALGERIA
}

${ }^{\star}$ Corresponding Author: Dr. Mustapha Haddouche, Laboratory of Applied Molecular Biology and Immunology BIOMOLIM, Department of Biology, University of Abou-Bekr Belkaid, Tlemcen 22, Abi Ayed Abdelkrim street, BP 119, Faubourg Pasteur13000 Tlemcen, Algeria; E-mail: haddouchemustapha2004@yahoo.fr

Received: February 09, 2020; Accepted: February 17, 2020; Published: February 19, 2020

\begin{abstract}
Introduction: Cancer has an extremely important human and socio-economic impact. It is due to several cellular disturbances causing uncontrollable proliferation, which stimulate immune system elements including monocytes that can play a dual role either in the elimination or progression of cancer cells [1], these disturbances affect a variety of functions such as glucose metabolism [2].
\end{abstract}

Keywords: Liver cancer, Monocyte, GOx, Cytokines. Cholesterol

\section{Objectives}

This work hopes to investigate the effect of glucose oxidase at the level of the monocyte on the tumor growth thus determining its impact on the glycolysis activity and on the mitochondrial metabolism.

Aim: The aim of this study is to show the role of GOx in the polarization of monocytes in contact with tumor cells.

\section{Materials and methods}

Monocytes isolated from the blood of the cancer patient were cocultured with the tumor epithelial cells isolated from a biopsy of the liver cancer, in a culture medium supplemented or not with GOx.

\section{Results}

GOx induced an increase in the INF- $\gamma$ and decrease of IL-10 as well as in NO and Arginase in the presence of Glucose oxidase compared to thus without GOx, the Cholesterol in microenvironment was decreased in presence of GOx.

\section{Conclusion}

In conclusion, our results showed an pro-inflammatory effect was reported in monocytes in contact with liver tumor epithelial cells.

\section{References}

1. Elliott LA, Doherty GA, Sheahan K, Ryan EJ (2017) Human Tumor-Infiltrating Myeloid Cells: Phenotypic and Functional Diversity. Front Immunol 8. [Crossref]

2. Annibaldi A, Widmann C (2010) Glucose metabolism in cancer cells. Curr Opin Clin Nutr Metab Care 13: 466-470. [Crossref] 